\title{
HAK KEWARISAN BAGI AHLI WARIS YANG MELAKUKAN OPERASI PENYESUAIAN KELAMIN GANDA (KHUNTSA) DALAM TINJAUAN HUKUM ISLAM
}

\author{
Wiwit Widya Wirawati dan Abdullah Kelib
}

\begin{abstract}
ABSTRAK
Allah SWT telah menetapkan aturan mengenai masalah kewarisan secara jelas dan tegas dalam Al-Quran Surat An-Nisa ayat 11. Dimana dijelaskan tentang pembagian warisan berdasarkan jenis kelamin laki-laki dan perempuan yaitu 2:1 (Das Sollen). Namun ternyata terdapat sekelompok orang yang disebut Khuntsa (berkelamin ganda). Baik dalam Al-Quran dan Hadist tidak dijelaskan ketentuan mawaris bagi ahli waris khuntsa dan jumlah besar bagian yang mereka terima (Das Sein). Perumusan masalah dalam penulisan ini adalah bagaimana kewarisan bagi ahli waris yang melakukan operasi kelamin ganda (khuntsa) sesuai KHI dan bagaimana hak yang seharusnya diberikan kepada ahli waris yang melakukan operasi penyesuaian kelamin ganda (khuntsa) sesuai dengan Hukum Islam.

Penelitian ini menggunakan metode pendekatan yuridis normatif dengan spesifikasi penelitian secara deskriptif analitis. Sumber dan jenis data adalah data sekunder yang diperoleh dari norma-norma hukum Islam tentang kewarisan dan khuntsa yang diperoleh dari Al-Quran, Hadist, KHI, serta pendapat fuqaha dan ahli dalam berbagai literatur tentang kewarisan dan khuntsa.

Berdasarkan hasil penelitian, hak kewarisan khuntsa secara tegas tidak diatur dalam KHI. Sehingga apabila khuntsa melakukan operasi penyesuaian kelamin, dan diperoleh kejelasan status hukumnya maka hak kewarisannya sesuai dengan yang ditentukan dalam Pasal 176 KHI. Ketentuan mawaris bagi ahli waris khuntsa dalam Hukum Islam adalah khuntsa terlebih dahulu diperkirakan sebagai laki-laki kemudian perempuan. Khuntsa dan ahli waris lain mendapat bagian atas perkiraan yang terkecil dan meyakinkan, sedang sisanya yang masih diragukan ditahan sampai status hukum khuntsa menjadi jelas. Apabila persoalan khuntsa jelas, penerimaan semua ahli waris disempurnakan dengan menambahkan bagian kepada mereka yang berkurang menurut penerimaan yang seharusnya mereka terima. Kedepannya formulasi KHI harus mengatur mengenai hak kewarisan khuntsa beserta besarnya bagian waris yang diterima.
\end{abstract}

Kata kunci : warisan khuntsa, operasi kelamin, hukum islam. 


\title{
THE RIGHTS OF INHERITANCE FOR HEIRS CONDUCTING DOUBLE GENITAL ADJUSTMENT SURGERY (KHUNTSA) IN ISLAMIC LAW REVIEW
}

\author{
Wiwit Widya Wirawati and Abdullah Kelib
}

\begin{abstract}
Allah SWT has set the rules on the issue of inheritance clearly and firmly in Al-Qur'an Surah An-Nisa article 11. It explains about the division of inheritance based on male and female sex, that is 2:1 (Das Sollen). But in fact there is a group of people called Khuntsa (double sex). Neither in Al-Qur'an nor Hadist explains the provisions of inheritance for khuntsa heirs and the large number of parts they receive (Das Sein). The formulation of the problem in this study is how inheritance for the heirs who perform double genital surgery (khuntsa) according to KHI and how the right should be given to the heirs who perform double genital adjustment surgery (khuntsa) in accordance with Islamic Law.

This research uses juridical normative approach method with analytical descriptive research specification. Sources and types of data are secondary data obtained from Islamic legal norms on inheritance and khuntsa obtained from Al-Quran, Hadist, KHI, and fuqaha and experts opinions in various literature on inheritance and khuntsa.

Based on the research result, khuntsa inheritance right is not regulated in KHI. Theredore if khuntsa conducts genital adjustment surgery, and get the clarity of its legal status hence its right of inheritance is as specified in Article $176 \mathrm{KHI}$. The provision of inheritance for khuntsa heirs in Islamic Law is khuntsa first predicted as male then female. Khuntsa and other heirs share the smallest and most convincing estimates, while the remaining doubts are held until the status of the khuntsa law is clear. If the khuntsa matter is clear, the acceptance of all the heirs is perfected by adding share to those who are reduced according to the acceptance they should receive. In the future, the formulation of KHI should regulate the right of khuntsa inheritance along with the amount of the inheritance received.
\end{abstract}

Keywords: khuntsa heritage, genital surgery, Islamic law.

\section{A. Latar Belakang}

Kewarisan dalam hukum

Islam merupakan hal yang essensial, karena menyangkut segala sesuatu yang ditinggalkan oleh seseorang yang meninggal dunia, baik berupa harta benda maupun hak-hak kebendaan. ${ }^{1}$ Mengingat essensialnya masalah kewarisan ini, maka Allah SWT

\footnotetext{
1 Amir Syarifuddin, Hukum Kewarisan Islam, (Jakarta : Prenada Media, 2005), hlm. 5-6.
}

menetapkan aturannya secara terang, jelas dan tegas dalam AL-Quran Surat An-Nisa ayat 11 bahwa bagian anak laki-laki dibandingkan anak perempuan adalah 2:1 (dua berbanding satu bagian). Penetapan ini bertujuan untuk memberikan kepastian hukum terhadap hak milik seseorang dengan cara yang seadil-adilnya. Al-Qur`an menetapkan hak kewarisan seseorang berdasarkan jenis kelamin yang dimilikinya, apakah 
laki-laki atau perempuan. Akan tetapi tidak dijelaskan secara rinci apa yang dimaksud dengan laki-laki atau perempuan itu. ${ }^{2}$ Tetapi dalam kenyataannya, terdapat seseorang yang tidak memiliki status yang jelas, bukan laki-laki dan bukan perempuan. Mereka adalah makhluk Allah yang disebut khuntsa. Khuntsa adalah "orang dengan alat kelamin ganda" atau "orang dengan ketidakjelasan alat kelamin". 3

Khuntsa termasuk dalam warisan ahli waris yang statusnya diragukan/ kasus tertentu. Yang dimaksud "ahli waris yang statusnya diragukan" adalah ahli waris yang pada saat harta warisan terbuka (pada saat si pewaris meninggal dunia) status hukumnya sebagai "subjek hukum" atau "sebagai pendukung hak dan kewajiban" masih diragukan. ${ }^{4}$ Al-Quran menetapkan hak kewarisan seseorang berdasarkan jenis kelamin yang dimilikinya, apakah laki-laki atau perempuan. Allah telah menjelaskan pula pusaka orang laki-laki dan perempuan sejelas-jelasnya di dalam Al-Quran. Tetapi ayat tersebut tidak

2 Muchit A. Karim, Problematika Hukum Kewarisan Islam Kontemporer di Indonesia, (Jakarta : Puslitbang Kehidupan Keagamaan, 2012), hlm. 374.

${ }^{3}$ Fatchur Rahman, Ilmu Waris, (Bandung :Alma'rif 1971), hlm. 482.

${ }^{4}$ Surahwa K. Lubis dan Komis Simanjutak, Hukum Waris Islam (Jakarta :Sinar Grafika, 2004). hlm. 60 . menjelaskan bagian seorang khuntsa. ${ }^{5}$ Khuntsa menurut Ulama Fiqih di bagi menjadi dua golongan yakni golongan khuntsa musykil dan khuntsa ghairu musykil. ${ }^{6}$

Salah satu penemuan dalam ilmu pengetahuan khususnya dalam bidang kedokteran yang berdampak pada hak waris bagi manusia adalah operasi penyesuaian kelamin. Operasi penyesuaian kelamin yang dimaksudkan disini merupakan tindakan perbaikan atau penyempurnaan kelamin untuk mengoptimalkan fungsi alat kelamin yang lebih dominan dari orang yang berkelamin ganda itu sendiri.. Pelaku pergantian kelamin lebih didominasi oleh khunsa atau mukhannats. ${ }^{7}$

Berdasarkan latar belakang tersebut, maka perumusan masalah dalam penelitian ini adalah sebagai berikut :

1. Bagaimana hak kewarisan bagi ahli waris yang melakukan operasi penyesuaian kelamin ganda (khuntsa) sesuai dengan Kompilasi Hukum Islam ?

\footnotetext{
${ }^{5}$ Fatchur Rahman, Opcit., hlm. 484.

${ }^{6}$ Ibid., hlm. 482.

7 Syamsul Mahmudin, Hak Waris Waria dalam Keluarga, (Online), (http://majalahforum.com/hukum.php?tid=112/, diakses pada tanggal 25 januari 2016).
} 
2. Bagaimana hak yang seharusnya diberikan kepada ahli waris yang melakukan operasi penyesuaian kelamin ganda (khuntsa) sesuai dengan Hukum Islam?

\section{B. Tujuan dan Manfaat Penelitian}

Tujuan yang diharapkan dari hasil penelitian ini adalah :

1. Untuk mengetahui dan menganalisis hak kewarisan bagi ahli waris yang melakukan operasi penyesuaian kelamin ganda (khuntsa) sesuai dengan Kompilasi Hukum Islam.

2. Untuk mengetahui dan menganalisis hak yang seharusnya diberikan kepada ahli waris yang melakukan operasi penyesuaian kelamin ganda (khuntsa) sesuai dengan Hukum Islam.

Beranjak dari tujuan
sebagaimana tersebut diatas, maka
diharapkan penelitian ini akan
memberikan manfaat sebagai berikut:

a. Secara Teoritis :

Hasil penelitian ini diharapkan dapat sebagai bahan masukan dan sumbangan pemikiran baik berupa pembendaharaan konsep, metode preposisi, maupun pengembangan teori-teori dalam bidang ilmu hukum khususnya mengenai Hukum Waris.

b. Secara Praktis :
Hasil penelitian ini diharapkan dapat memberikan jalan keluar dari permasalahan yang dihadapi khususnya terhadap kajian Hukum Islam mengenai hak kewarisan bagi ahli waris yang melakukan operasi penyesuaian kelamin ganda (khuntsa) dan merupakan bahan masukan bagi pihak-pihak tertentu dalam memutuskan suatu kebijakan.

\section{Metode Penelitian}

\section{Metode Pendekatan}

Metode pendekatan yang dipergunakan dalam penelitian tentang "Hak Kewarisan Bagi Ahli Waris Yang Melakukan Operasi Penyesuaian Kelamin Ganda (Khuntsa) Dalam Tinjauan Hukum Islam" adalah yuridis normatif, yaitu suatu penelitian yang bersifat doktrinal, dimana peninjauannya ditekankan dari segi yuridis. Penulis akan menggunakan datadata sekunder dengan jalan inventarisasi pendapat-pendapat ahli, artikel-artikel, tulisan-tulisan ilmiah dan referensi lainnya yang relevan dengan masalah yang diteliti. Dari data-data yang terhimpun selanjutnya akan dibahas secara lebih mendalam dari segi hukumnya. 
2. Spesifikasi Penelitian

Spesifikasi $r$ penelitian
yang dipergunakan $r$ dalam
penyusunan tesis ini adalah
penelitian dengan penguraian
secara deskriptif analitis yaitu
memaparkan, menggambarkan atau
mengungkapkan data-data
mempunyai relevansi, khususnya
dalam hak waris bagi ahli waris
yang melakukan $\quad$ operasi
penyesuaian kelamin ganda
(khuntsa) dalam tinjauan hukum
Islam. Hal tersebut kemudian
dibahas atau dianalisis menurut
ilmu dan teori-teori atau pendapat
peneliti sendiri dan terakhir
menyimpulkannya.

\section{Sumber dan Jenis Data}

Berkaitan dengan jenis penelitian yang dilakukan penulis yang merupakan penelitian normatif, maka jenis data yang digunakan di dalam penelitian ini adalah data sekunder. Data sekunder ini diperoleh dari bahan hukum primer, bahan hukum sekunder dan bahan hukum tersier yang meliputi :

1. Bahan Hukum Primer

$$
\begin{aligned}
& \text { Bahan hukum primer } \\
& \text { adalah bahan hukum yang } \\
& \text { mempunyai kekuatan mengikat } \\
& \text { secara yuridis, adapun yang }
\end{aligned}
$$

penulis gunakan dalam bahan hukum primer adalah:

a. Al- Quran dan Al-Hadist

b. Ijtihad para ulama yang terdiri dari Ijma dan Qiyas, merupakan sumber hukum tambahan dalam hukum waris Islam untuk menjelaskan suatu peristiwa atau keadaan yang kurang jelas atau tidak diatur dalam Al-Qur'an dan Hadist.

c. Kompilasi Hukum Islam yang terdapat dalam Instruksi Presiden RI No. 1 Tahun 1991 tanggal 10 Juni 1991

d. Kitab Undang-undang Hukum Perdata

e. UU No.7 Tahun 1989 jo. UU No. 3 Tahun 2006 jo. UU No. 50 Tahun 2009 tentang Pengadilan Agama

f. Keputusan Menteri Agama RI No. 154 Tahun 1991 tentang Pelaksanaan Instruksi Presiden No. 1 Tahun 1991

\section{Bahan Hukum Sekunder}

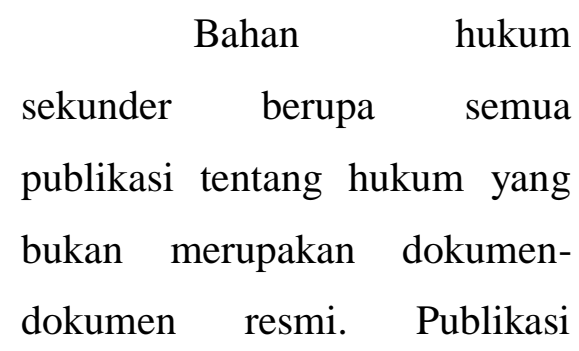


tentang hukum meliputi bukubuku teks, kamus-kamus hukum, jurnal-jurnal hukum dan komentar-komentar atas putusan pengadilan. Bahan hukum sekunder yang digunakan dalam penulisan hukum ini antara lain buku-buku yang terkait dalam penelitian ini, karya ilmiah, makalah, artikel dan lain sebagainya yang berkaitan dengan permasalahan yang diteliti.

3. Bahan Hukum Tersier

Bahan hukum yang
memberikan petunjuk atau
penjelasan terhadap bahan
hukum primer dan bahan hukum
sekunder, dalam hal ini berupa
kamus hukum maupun media
internet yang relevan dengan
penelitian ini.

4.

Teknik Pengumpulan

\section{Data}

Teknik pengumpulan data adalah dengan pengumpulan bahan hukum primer, bahan hukum sekunder, dan bahan hukum tersier, serta bagaimana bahan hukum tersebut diinventarisasi dan diklarifikasi dengan menyesuaikan terhadap masalah yang dibahas. Bahan hukum yang berhubungan dengan masalah yang dibahas dipaparkan, disistemisasi, kemudian dianalisis untuk menginterprestasikan hukum yang berlaku.

5. Teknik Analis Data Teknik analisis data merupakan cara menganalisis data penelitian, termasuk alat-alat statistik yang relevan untuk digunakan dalam penelitian. Dalam penelitian hukum ini, penulis menggunakan teknik analisis data kualitatif.

\section{Hasil Penelitian Dan Pembahasan}

1. Hak Kewarisan Bagi Ahli Waris Yang Melakukan Operasi Penyesuaian Kelamin Ganda (Khuntsa) Sesuai Dengan Kompilasi Hukum Islam

Berdasarkan firman Allah SWT dalam QS. An Nisa ayat 7, dimana dijelaskan bahwasanya setiap orang berhak menerima warisan dari harta peninggalan Bapa, Ibu dan kerabat menurut bagian yang telah ditetapkan. Di dalam Al-Quran, dalam ayat-ayat mawaris, tidak disebutkan bahwa khuntsa dikecualikan dalam pembagian warisan. Penjelasan mengenai QS. An-Nisa ayat 7 tersebut secara secara tidak langsung dengan menyebutkan bahwa setiap orang berhak menerima 
harta warisan tanpa terkecuali bahkan termasuk di dalamnya adalah seorang khuntsa memberikan pengertian mengenai penegakan keadilan bagi semua orang dimana keadilan merupakan salah satu ajaran pokok dalam Islam yang bersifat universal.

Penetapan kewarisan

orang khuntsa menurut cara/jalan kencingnya adalah telah menjadi kesepakatan atau ijmak para fuqaha dan juga faradliyun. Apabila tandatanda di atas bisa diketemukan dengan mudah, maka jelaslah status khuntsa tersebut (laki-laki atau perempuan), ini disebut khuntsa ghoirul musykil. Tetapi apabila setelah diteliti tanda-tanda tersebut masih meragukan, maka ia di sebut khuntsa musykil. ${ }^{8}$

Operasi kelamin yang
dilakukan pada seorang yang
mengalami kelainan kelamin
(misalnya berkelamin ganda) dengan
tujuan tashih atau takmil (perbaikan
atau penyempurnaan) dan sesuai
dengan hukum akan membuat
identitas dan status hukum orang
tersebut menjadi jelas. Bagi seorang
Khuntsa wajib baginya untuk melakukan operasi penyesuaian

8 Muslih Maruzi, Pokok-Pokok Ilmu Waris, (Semarang : Mujahidin, 1981), hlm. 1. kelamin dengan tujuan untuk menyempurnakan/ mempertegas identitasnya sebagai manusia dan subyek hukum baik dalam hal perkawinan maupun kewarisan. Setelah melalui serangkaian tindakan medis yang berkaitan dengan operasi kelamin, maka wajib bagi seorang Khuntsa yang sudah memiliki kejelasan jenis kelamin untuk meminta penetapan dari Pengadilan Negeri dan/atau Pengadilan Agama sebagai dasar hukum untuk menetapkan status hukumnya pasca operasi kelamin apakah sebagai lelaki atau perempuan agar ada kepastian hukumnya dan menghindari sifat mendua dalam pergaulan dan jenis kelamin yang sudah jelas ini kemudian ditegaskan dalam kartu identitas seperti KTP, SIM, ATM, dan sebagainya. ${ }^{9}$

Menurut penulis, operasi penyesuaian kelamin merupakan jalan keluar dari permasalahan keragu-raguan akan kepastian hukum status khuntsa. Operasi penyesuaian kelamin diperlukan bahkan dianjurkan bagi seorang khuntsa guna mendapatkan kepastian hukum akan status kelaminnya apakah laki-

\footnotetext{
${ }^{9}$ Bagus Prasetyo Purnomo Putro, Tinjauan Yuridis Perkawinan Al-Khuntsa (Kelamin Ganda) Menurut Hukum Islam, (Jember : Universitas Jember, 2013), hlm. 8 .
} 
laki atau perempuan. Dikarenakan keadaan khuntsa yang mempunyai kelamin ganda, maka dalam hal kewarisan terdapat keragu-raguan dalam penetapan hak waris dan bagian pusakanya. Sehingga, demi kemaslahatan bersama semua pihak dilakukan operasi penyesuaian kelamin demi diperolehnya kepastian hukum. Apabila khuntsa telah melakukan operasi penyesuaian kelamin dan diperoleh kejelasan status kelaminnya, maka sudah terjaminlah kepastian hukum si ahli waris khuntsa baik mengenai jenis kelaminnya yang sudah pasti di mata hukum dimana akan berdampak pada banyak aspek kehidupan seperti perkawinan dan kewarisannya.

Apabila diperhatikan, dari keseluruhan pasal-pasal yang mengatur mengenai ahli waris dan bagiannya dalam Kompilasi Hukum Islam, tidak ada satupun pasal yang menyebutkan ataupun membahas mengenai ketentuan hukum waris bagi khuntsa. Hal ini menjadikan pengaturan waris khuntsa dalam hukum positif Indonesia belum pasti akan tetapi merunut pada fakta pasca terjadinya operasi penyesuaian kelamin oleh khuntsa yang mana untuk lebih memperjelas status hukumnya. Maka setelah menjalani operasi penyesuaian kelamin, apabila menjadi jelas statusnya sebagai lakilaki maka dia memperoleh 2 (dua) bagian dari harta warisan. Sebaliknya jika setelah operasi penyesuaian kelamin menjadi perempuan statusnya maka dia memperoleh 1 (bagian) dalam hak kewarisannya.

Hal tersebut didasarkan pada Pasal 174 KHI, penentuan hak kewarisan ditentukan berdasarkan golongan jenis kelamin sebagai lakilaki dan sebagai perempuan, sehingga ahli waris khuntsa yang sebelum melakukan operasi penyesuaian kelamin, jenis kelaminnya masih diragukan apakah laki-laki atau perempuan, maka setelah operasi penyesuaian kelamin statusnya menjadi jelas dan sah di mata hukum terlebih setelah mendapatkan penetapan di Pengadilan Negeri/ Pengadilan Agama mengenai status hukumnya. Bila khuntsa telah jelas status hukumnya berarti ia hukumnya lelaki atau perempuan, maka berlakulah hukum lelaki atau perempuan baginya dalam segala hal, seperti auratnya, shalatnya, perkawinannya, kewarisannya, pergaulannya dan sebagainya. 
Oleh karena itu, besarnya bagian ahli waris khuntsa pasca operasi penyesuaian kelamin disesuaikan dengan besarnya bagian dalam hak kewarisan sebagaimana yang diatur dalam Pasal $176 \mathrm{KHI}$, dimana anak perempuan bila hanya seorang ia mendapat separoh bagian, bila dua orang atau lebih mereka bersama-sama mendapat dua pertiga bagian, dan apabila anak perempuan bersama-sama dengan anak laki-laki, maka bagian anak laki-laki dua berbanding satu dengan anak perempuan.

\section{Hak Yang Seharusnya Diberikan}

\section{Kepada Ahli Waris Yang} Melakukan Operasi Penyesuaian Kelamin Ganda (Khuntsa) Sesuai Dengan Hukum Islam

Al-Quran menetapkan hak kewarisan seseorang berdasarkan jenis kelamin yang dimilikinya, apakah sebagai laki-laki atau perempuan. Allah telah menjelaskan pula pusaka orang laki-laki dan perempuan sejelas-jelasnya di dalam Al-Quran. Tetapi tidak menjelaskan bagian seorang khuntsa. Dasar kewarisan anak laki-laki dan dan perempuan adalah firman Allah dalam surat An-Nisa ayat 11 . Mengenai ketentuan kadar perhitungan waris bagi khuntsa musykil para ulama' ahli faroi'd ikhtilaf (mencari jalan keluar) dengan mengidentifikasi perkiraan sebagai laki-laki dan sebagai perempuan. Tapi kemudian mereka berselisih pendapat dalam menerimakan bagian khuntsa musykil setelah di ketahui dua pekiraan.

Penulis sendiri lebih sepakat dengan ketentuan kadar penghitungan waris bagi khuntsa musykil dalam kalangan madzhab Syafi'iyah yaitu bagian setiap ahli waris dan khuntsa diberikan dalam jumlah yang paling sedikit. Karena pembagian seperti ini lebih meyakinkan bagi tiap-tiap ahli waris. Sedangkan sisanya (dari harta waris yang ada) untuk sementara tidak dibagikan kepada masing-masing ahli waris hingga telah nyata keadaan yang semestinya.

Apabila persoalan khuntsa jelas, penerimaan semua ahli waris disempurnakan dengan menambahkan bagian kepada mereka yang berkurang menurut penerimaan yang seharusnya mereka terima. Bila sampai waktu cukup tapi status khuntsa belum jelas maka semua ahli waris mengadakan perundingan damai (islah) untuk 
saling memberikan terhadap sisa yang ditahan. Sebab tanpa perundingan tidak ada jalan/cara yang dapat mengesahkan/ menghalalkan. Dan perundingan semacam ini adalah boleh/ sah, kendatipun menurut syarat hibah itu harus diketahuinya secara yakin sesuatu yang dihibahkan, berdasarkan kebutuhan atau darurat. Bila khuntsa diperkirakan dengan salah satu perkiraan menjadi terhalang, maka khuntsa itu dilarang menerima warisan (mahrum /mahjub). Dan bila salah satu ahli waris terhalang oleh perkiraan khuntsa lelaki atau perempuan, maka khuntsa tetap terhalang. ${ }^{10}$

Jika dikaitkan dengan teori kepastian hukum, maka dalam menetapkan suatu hukum haruslah meyakinkan dan jauh dari keraguraguan. Yang pada dasarnya kehatihatian itu lebih meyakinkan demi kemaslahatan, dengan alasan yang tepat, menurut penulis penerapan kadar penghitungan waris bagi khuntsa untuk membagikan harta yang terkecil kepada khuntsa dan ahli waris dengan menangguhkan sisa harta pembagian tersebut lebih meyakinkan kepada setiap ahli

\footnotetext{
${ }^{10}$ Fatchur Rahman, Opcit., hlm. 488.
}

waris, sampai jelas status khuntsa tersebut laki-laki atau perempuan kemudian dibagikan terhadap ahli waris yang berhak. Apabila status khuntsa tetap tidak menjadi jelas agar mencapai kemaslahatan bersama, maka harus diadakan perjanjian tawahub (saling menghibahkan) para ahli waris, menurut penulis hal itu lebih mencerminkan rasa keadilan tanpa saling merugikan satu sama lain.

Ada sedikit catatan kaitannya dengan konsep al ahliyah al-wujub dalam bagian waris 2:1 antara laki-laki dengan perempuan. Konsep ini perlu dintergrasikan dengan kondisi sosial masyarakat kita sekarang. Dalam Kompilasi Hukum Islam, konsep bagian waris 2:1 antara laki-laki dengan perempuan masih berlaku, terutama Pasal 176-180. Ketentuan pembagian waris sama rata (1:1) antara laki-laki dengan perempuan dapat berlaku hanya dalam hal yang bersifat kasusistik. Ketentuan ini dapat digunakan oleh Hakim-Hakim dalam ringkup Peradilan Agama yang berhadapan langsung dengan permasalahan-permasalahan yang beraneka ragam terjadi pada masyarakat. 
Tidak tercantumnya pasal yang mengatur mengenai hak waris dan besaran waris khuntsa dalam KHI jelas bertentangan dengan prinsip keadilan dalam Islam. Keadilan dalam hukum Islam digantungkan pada keadilan yang telah ditentukan oleh Allah Swt, karena tidak mungkin manusia mengetahui keadilan itu secara benar dan tepat. Dalam hukum Islam, keimanan mendahului pengertian, karena telah ditetapkan bahwa segala yang ditetapkan Allah Swt pasti adil. Sedangkan keadilan dalam hukum positif sepenuhnya digantungkan pada penalaran manusia. Oleh karena itu masuk dalam ranah filsafat hukum, dan karena itu pula pengertian keadilan selalu berubah dari masyarakat satu ke masyarakat yang lain, tergantung pada aliran filsafat hukum yang dianut oleh masyarakat tersebut. ${ }^{11}$

Menurut penulis, sebuah keputusan hukum dikatakan adil jika berangkat dari pedoman Al-Qur'an dan Hadits serta tidak bertentangan dengan prinsip keadilan secara umum, karena keterikatan muslim dengan pedoman dasar pengambilan

${ }_{11}$ Bustanul Arifin, Pelembagaan Hukum Islam di Indonesia, (Jakarta: Gema Insani Press, 1996), hlm. 45-46. keputusan mempunyai pengaruh yang mendasar terhadap kehidupan muslim secara individual maupun sosial. Walaupun hak kewarisan khuntsa dalam Al-Quran maupun Hadist tidak dijelaskan secara gamblang, akan tetapi para ulama telah berijtihad untuk menentukan hak kewarisan bagi khuntsa dengan berpedoman pada Al-Quran dan Hadist. Apabila hak kewarisan khuntsa tersebut berangkat dari pedoman Al-Quran dan Hadist mengapa tidak terdapat pengaturan mengenai hak kewarisan dan besaran waris khuntsa di dalam KHI, padahal dibentuknya KHI juga berdasarkan/berpedoman pada AlQuran dan Hadist. Jelas ketiadaan pengaturan mengenai hak waris khuntsa dalam KHI merupakan suatu bentuk ketidakadilan bagi seorang khuntsa, padahal seorang khuntsa juga merupakan makhluk ciptaan Tuhan, walau belum didapat jelas kepastian jenis kelaminnya namun dia tetaplah seorang manusia yang dijamin hak-hak-nya tanpa dibedabedakan sebagai makhluk ciptaan Tuhan baik dalam Al-Quran, Hadist maupun dalam UUD RI 1945 Pasal 28.

Keadilan bagi seorang khuntsa baru didapatkan pasca dia 
melakukan operasi penyesuaian kelamin. Karena setelah dilakukannya operasi penyesuaian kelamin tersebut barulah didapatkan kejelasan mengenai status kelamin si khuntsa apakah sebagai laki-laki atau sebagai perempuan. Dikarenakan dalam KHI, hanya dimuat pasal mengenai pembagian waris berdasarkan golongan jenis kelamin, maka setelah operasi penyesuaian kelamin si khuntsa baru mendapat keadilan dengan disesuaikan hak kewarisannya sesuai dengan yang diatur dalam KHI.

Akan tetapi menurut hemat penulis, hal tersebut dirasa belum terjadi keadilan terutama bagi khuntsa sebelum dia melakukan operasi penyesuaian kelamin. Menurut penulis, alangkah baiknya pengaturan mengenai hak kewarisan dan juga bagian waris khuntsa sebelum melakukan operasi penyesuaian kelamin juga diatur di dalam KHI dengan menggunakan salah satu madzab yang diyakini dalam ketentuan pembagian waris khuntsa. Sehingga, tidak hanya ada pengaturan mengenai hak waris seseorang yang normal kelaminnya dimana di dalamnya dalam kasus khuntsa pasca operasi juga termasuk. Namun juga mengenai khuntsa sebelum operasi penyesuaian kelamin juga harus diatur dan ditetapkan sehingga diperoleh keadilan yang seadil-adilnya di mata hukum berdasarkan dengan AlQuran, Hadist dan juga Ijtihad para ulama.

\section{E. Simpulan}

Bagi seorang Khuntsa wajib baginya untuk melakukan operasi penyesuaian kelamin dengan tujuan untuk mempertegas identitasnya sebagai manusia dan subyek hukum. Hak kewarisan khuntsa tidak diatur secara tegas di dalam KHI. Akan tetapi merunut pada fakta pasca terjadinya operasi penyesuaian kelamin oleh khuntsa yang mana untuk lebih memperjelas status hukumnya dan diperoleh ketetapan hukum akan statusnya sebagai laki-laki atau perempuan. Berdasarkan Pasal 174 KHI, penentuan hak kewarisan ditentukan berdasarkan golongan jenis kelamin sebagai laki-laki dan sebagai perempuan. Kemudian besarnya bagian dalam hak kewarisan sesuai Pasal 176 KHI, dimana anak perempuan bila hanya seorang ia mendapat $1 / 2$ bagian, bila dua orang atau lebih mereka bersama-sama mendapat $2 / 3$ bagian, dan apabila anak perempuan bersamasama dengan anak laki-laki, maka 
bagian anak laki-laki dua berbanding satu dengan anak perempuan.

Al-Quran menetapkan hak kewarisan seseorang berdasarkan jenis kelamin yang dimilikinya, apakah sebagai laki-laki atau perempuan. Dasar kewarisan anak laki-laki dan dan perempuan adalah firman Allah dalam surat An-Nisa ayat 11 yaitu bagian anak laki-laki sama dengan bagian dua orang anak perempuan. Seorang ahli waris khuntsa apabila telah melakukan operasi penyesuaian kelamin dan telah mendapat kejelasan mengenai status kelaminnya sebagai laki-laki atau perempuan, maka sesuai dengan ketentuan yang disebutkan dalam AlQuran, ahli waris tersebut berhak untuk mendapatkan bagian warisannya secara penuh sesuai dengan ketentuan atau dengan kata lain, bagian waris yang sebelumnya ditangguhkan saat masih seorang khuntsa, setelah diperoleh kepastian statusnya hak waris yang ditangguhkan tersebut diberikan secara penuh sesuai dengan ketentuan.

\section{F. Saran}

Berdasarkan hasil penelitian yang dilakukan. Saran yang direkomendasikan sebagai berikut :

1. Bagi pemerintah, sekiranya pemerintah perlu membuat langkahlangkah terkait khuntsa, seperti menetapkan peraturan mengenai hak kewarisan dan bagian harta pusaka kepada khuntsa musykil ke dalam perundang-undangan hukum waris di Indonesia terutama dalam Kompilasi Hukum Islam (KHI) sesuai dengan ketentuan madzab yang telah ditentukan.

2. Bagi aparat penegak hukum dalam perspektif memberikan putusan hak waris diutamakan melihat pada asas dan aspek kepastian hukum sesuai dengan konstitusi. Sehingga diperoleh keadilan bagi ahli waris khuntsa dalam mendapatkan hak waris dapat diberikan secara proporsional.

3. Bagi masyarakat, sudah sepatutnya mengetahui tentang keberadaan khuntsa ini dan bisa menerima mereka dengan sepatutnya tanpa ada diskriminasi terhadap mereka. Karena pada dasarnya, mereka memang ada di tengah-tengah kita, dan mereka juga mempunyai hak yang sama dengan kita. Mereka mempunyai status yang jelas dan diakui oleh Islam, sehingga mereka juga mempunyai peran dalam mendapatkan hak mereka dalam segala hal. 


\section{DAFTAR PUSTAKA}

\section{Buku :}

Muchit A. Karim, 2012, Problematika

Hukum Kewarisan Islam

Kontemporer di Indonesia, Jakarta :

Puslitbang Kehidupan Keagamaan.

Surahwa K. Lubis dan Komis Simanjutak, 2004, Hukum Waris Islam, Jakarta :Sinar Grafika.

Fatchur Rahman, 1975, Ilmu Waris, Alma'rif : Bandung.

Ahmad Rofik, 1998, Fiqih Mawaris, Jakarta : Raja Grafindo Persada.

Muslih Maruzi, 1981, Pokok-Pokok Ilmu Waris, Semarang : Mujahidin.

Bustanul Arifin, 1996, Pelembagaan Hukum Islam di Indonesia, Jakarta: Gema Insani Press.

Syarifuddin, Amir, 2008, Hukum Kewarisan Islam, Kencana Prenada Media, Jakarta.

\section{Jurnal}

Bagus Prasetyo Purnomo Putro, 2013, Tinjauan Yuridis Perkawinan AlKhuntsa (Kelamin Ganda) Menurut Hukum Islam, Jember : Universitas Jember.

Bambang Widhiatmoko \& Edy Suyanto, 2013, Legalitas Perubahan Jenis Kelamin Pada Penderita Ambiguous Genetalia di Indonesia, Jurnal Kedokteran Forensik Indonesia, Vol. 15 No. 1 Maret 2013, Surabaya : Universitas Airlangga.

\section{Internet}

Syamsul Mahmudin : Hak Waris Waria dalam Keluarga. Diunduh pada 25 Januari 2016 jam 14.00 WIB dari situs http://majalahforum.com/hukum.php ?tid=112/. 